Article

\title{
Sustainability Assessment of Using Recycled Aggregates in Concrete Block Pavements
}

\author{
Md Mizanur Rahman * ${ }^{\mathbb{D}}$, Simon Beecham ${ }^{\circledR}$, Asif Iqbal, Md Rajibul Karim \\ and Abu Taher Zillur Rabbi \\ Geotechnical Engineering, University of South Australia, UniSA STEM, Mawson Lakes, SA 5095, Australia; \\ simon.beecham@unisa.edu.au (S.B.); asif.iqbal@mymail.unisa.edu.au (A.I.); \\ rajibul.karim@unisa.edu.au (M.R.K.); zillur.rabbi@mymail.unisa.edu.au (A.T.Z.R.) \\ * Correspondence: mizanur.rahman@unisa.edu.au
}

Received: 26 April 2020; Accepted: 22 May 2020; Published: 25 May 2020

check for updates

\begin{abstract}
The mechanistic design of a concrete block pavement (CBP) can be very complicated and often requires the use of computer programs. This paper presents a new mechanistic-empirical method, which is implemented in a computer program (DesignPave) that calculates base course/sub-base thicknesses for a range of design inputs such as traffic load, interlocking properties, and material stiffness. A range of virgin and recycled unbound granular materials were also experimentally tested to characterize them for possible use as base course or sub-base materials. Combining the new mechanistic-empirical method and the range of base course/sub-base course materials (virgin and recycled aggregates), it was found that while a CBP containing recycled aggregates did not offer a significant direct financial benefit based on the characteristics or material costs, the associated environmental benefits were very high.
\end{abstract}

Keywords: concrete block pavements; mechanistic design; recycled aggregates; eco-efficiency

\section{Introduction}

Segmental paving has been in use since the 18th century when stone setts quarried from granite, basalt, sandstone, or limestone were used in paving operations [1-3]. Because of the high cost of stone and, to some extent, to reduce some of the noise issues related to stone block pavement, the use of vitrified brick pavements started in the early 19th century in Europe, particularly in Germany and the Netherlands [4,5]. A major development in concrete block pavement (CBP) technology came in the mid-20th century in Europe when increased mechanization and automation in the production of concrete block pavements proved to be beneficial in terms of cost-effectiveness compared to the other form of segmental pavements. This led to the adaptation of CBP technology in America, South Africa, Australia, New Zealand, and Japan [4].

CBP differs from other forms of concrete pavement in that it comprises a layer of rigid paving blocks, which can be either pervious or impervious, laid either on a sand or fine-gravel bedding course [6]. CBPs are commonly used in road and industrial applications. They are often treated as a form of flexible pavement. However, there are behavioral differences, for example, the joints of these pavers create an "inter-locking" action and become stiffer and stronger with the progression of loading. Thus, the concepts and design principles for flexible pavements cannot be directly adapted for CBPs, and modifications are needed. This paper describes a new mechanistic-empirical method for the CBP design and its implementation into a computer program called DesignPave [7].

There are existing research and ongoing practices of using recycled aggregates substituting the virgin materials, which validates the applicability of using recycled aggregates in roads and pavements [8-10]. This article, rather than justifying the applicability of this substitution, 
evaluates the sustainability of using recycled aggregate by applying this new mechanistic-empirical method for the CBP design. The recycled materials are essentially the construction and demolition waste (CDW), which is processed in the recycling facility to prepare as road aggregates, containing various sizes of screened stone and rock $[9,11]$. The virgin road aggregates generally consist of $20 \mathrm{~mm}$ crushed rocks with fines, extracted from a quarry [11]. A large variety of recycled and virgin unbound granular materials for base course and sub-base use were characterized in the geotechnical laboratory at the University of South Australia. This provided material design parameters for both recycled and virgin base course/sub-base material that could be used in the evaluation of the economic and environmental benefits of using recycled aggregates. A case study of a $7000 \mathrm{~m}^{2}$ area of CBP, which was designed using this new mechanistic-empirical method and constructed using a virgin base course in 2016, was evaluated for economic and environmental benefits with different grades of recycled aggregate.

In terms of the sustainability of using different materials, a series of scenarios has also been considered to investigate the effects of different parameters such as aggregate source (recycled/virgin) of the base course/sub-base material under specific traffic loads and subgrade strengths.

\section{Methodology}

A number of mechanistic-empirical methodologies for CBP have been developed, and many of these have been implemented in computer programs [12-14]. The mechanistic-empirical methodologies for CBP are different than a flexible pavement (for example bituminous layers) [15]. The notable differences are:

- The deflection tolerance of bituminous layers in a flexible pavement structure is usually very small (to limit fatigue cracking), whereas CBPs can tolerate movements up to $2 \mathrm{~mm}$ without showing distress $[15,16]$.

- CBPs tend to interlock during the initial period of use after construction which improves their performance $[12,17,18]$. Modification of the vertical elastic modulus of concrete block paving layer over the course of its early life is also considered in CBPs [15,19].

- The conventional use of axle load equivalences (widely used in a flexible pavement) is deliberately avoided in the CBP, and instead, actual traffic spectrum loads are used.

The mechanistic-empirical design methodology and its implementation in freely available software, DesignPave, is briefly described below, including its use for evaluating the sustainability of CBP systems that include recycled aggregates.

\subsection{Mechanistic Design Methodology Implemented in DesignPave}

The algorithm for the mechanistic-empirical design method in DesignPave is presented schematically in Figure 1. The process can be explained using the following four steps: defining traffic load; choice of pavement layer system and material parameters in each layer; calculation of stresses and strains at the top of the semi-infinite subgrade layer; and application of the damage law for the design equivalent standard axle (ESA) load or traffic spectrum via Miner's rule. These steps are discussed in detail below. 


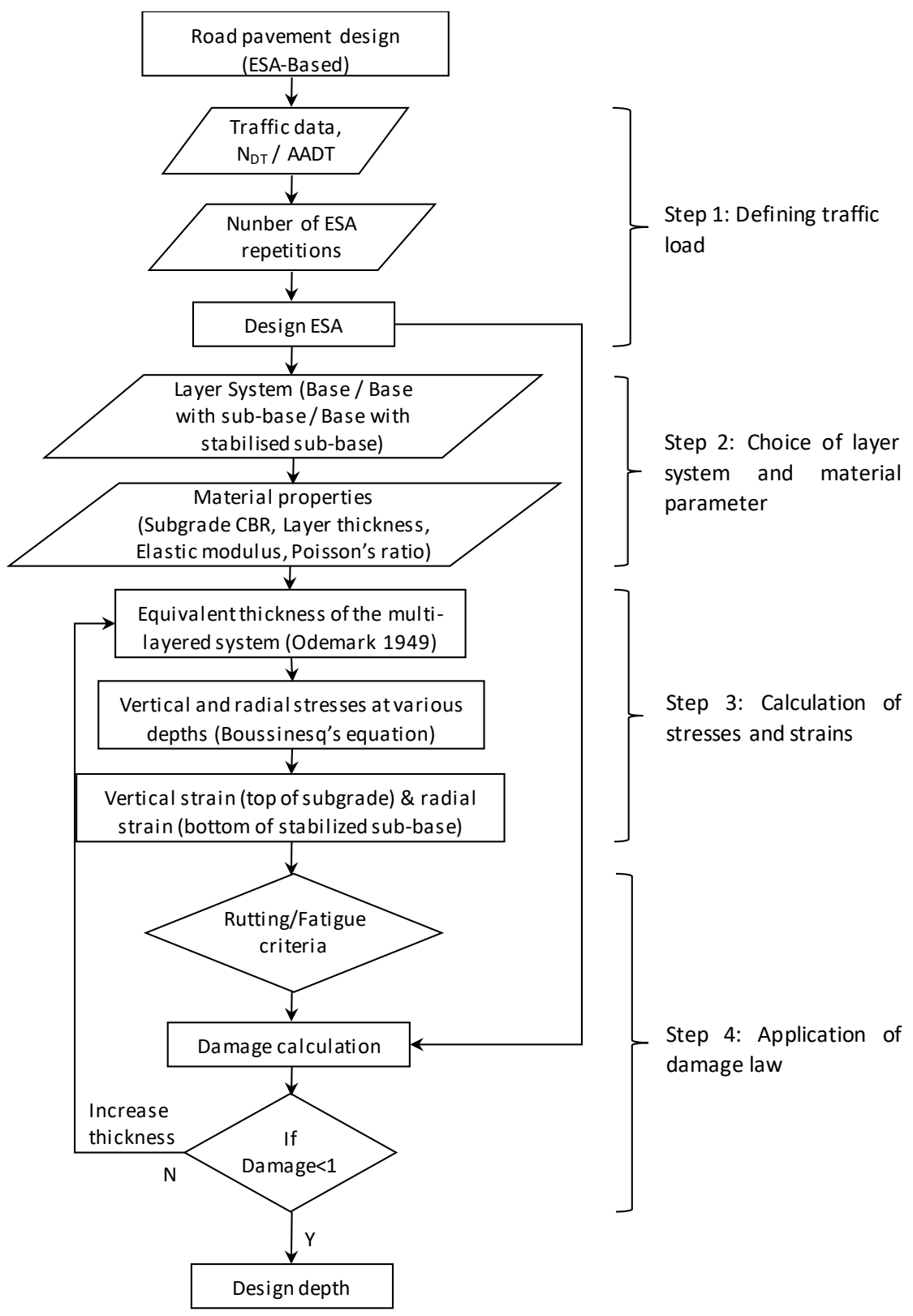

Figure 1. DesignPave flow chart for estimating base course/sub-base depths for different pavement materials under various traffic loading conditions. ESA: Equivalent Standard Axle, AADT: Annual Average Daily Traffic, CBR: California Bearing Ratio.

\subsubsection{Defining Traffic Load}

The first step in the process is the estimation of the total number of vehicle axle group repetitions over the design life $\left(\mathrm{N}_{\mathrm{DT}}\right)$. This can be a direct input by the user, or it can be calculated using the following equation, as proposed by Austroads [20]:

$$
N_{D T}=365 \times A A D T \times D F \times\left(\% \frac{H V}{100}\right) \times L D F \times C G F \times N_{H V A G}
$$

where $A A D T$ is the Annual Average Daily Traffic, $D F$ is the direction factor (proportion of two-way traffic travelling in the direction of the design lane), $\% \mathrm{HV}$ is the average percentage of heavy vehicles, $L D F$ is the land distribution factor (proportion of heavy vehicles in the design lane), CGF is the cumulative growth factor, and $N_{H V A G}$ is the average number of axle groups per heavy vehicle. 
According to Austroads [20], $C G F=\frac{(1+0.01 R)^{P}-1}{0.01 R}$ for $R>0$, where $R$ is the annual growth rate expressed as a percentage and $P$ is the design period in years. According to Austroads [20], $C G F=\frac{(1+0.01 R)^{P}-1}{0.01 R}$ for $R>0$, where $R$ is the annual growth rate expressed as a percentage and $P$ is the design period in years. It is assumed that $C G F=P$ for $R=0$. Either traffic load distribution or ESA can be used as a form of traffic load in practice, and thus both are implemented in the algorithm to compare their influence on the design. For this article, ESA was used for traffic load, and design ESA (DESA) was calculated by multiplying $\mathrm{N}_{\mathrm{DT}}$ with ESA/heavy vehicle axle groups (HVAG), i.e., indirectly adjusting damage on the pavement due to the axle groups of a traffic load distribution. The influence of traffic spectra on pavement damage was not a part of this study, although this is described elsewhere [21].

\subsubsection{Pavement Layer System and Material Properties}

The pavement layers in a CBP typically consist of 60-120 thick concrete block pavers, under which lies a $20-30 \mathrm{~mm}$ thick bedding sand layer. For permeable pavement systems, the bedding sand is typically replaced by 2-6 mm bedding gravel. Below this lies a base course gravel layer of minimum depth $100 \mathrm{~mm}$, and there may also be a sub-base course or a stabilized base course over the subgrade layer, depending on the traffic loading conditions, design life, and California bearing ratio (CBR) of the subgrade. The details of the pavement layer system and material properties used in this study are discussed in the following section. The choice of layers is important in the implementation of a mechanistic-empirical design method as it affects the stresses and strains at the subgrade layer.

\subsubsection{Calculation of Stresses and Strains}

Solutions for stresses in a homogenous half-space were developed by Boussinesq [22] for a point load at the surface. The solutions were then extended for circular wheel loads. The stresses and strains under the centre of the wheel load can be represented by the following equations, which were adopted in DesignPave [21]:

$$
\begin{gathered}
\sigma_{z}=P\left[\frac{z^{3}}{\left(a^{2}+z^{2}\right)^{3 / 2}}-1\right] \\
\sigma_{r}=\sigma_{t}=\frac{P}{2}\left[\frac{2 z(1+v)}{\left(a^{2}+z^{2}\right)^{1 / 2}}-\frac{z^{3}}{\left(a^{2}+z^{2}\right)^{3 / 2}}-(1+2 v)\right] \\
\varepsilon_{z}=\frac{1}{E}\left[\sigma_{z}-v\left(\sigma_{r}+\sigma_{t}\right)\right] \\
\varepsilon_{r}=\frac{1}{E}\left[\sigma_{r}-v\left(\sigma_{t}+\sigma_{z}\right)\right]
\end{gathered}
$$

where $a$ is the radius of the circular loading area, $p$ is the contact pressure, $z$ is the depth below the surface, and $v$ is the Poisson ratio. The vertical, radial, and tangential stresses are $\sigma_{z}, \sigma_{r}$, and $\sigma_{t}$, respectively, and $\varepsilon_{z}, \varepsilon_{r}$, and $\varepsilon_{t}$ are the vertical, radial, and tangential strains, respectively. Equations (2) and (3) are not directly applicable to multi-layered systems. To overcome this, the equivalent thickness method (ETM), as presented by Odemark [23], was adopted, which is shown in the equation:

$$
h_{e q}=n h_{i}\left(\frac{E_{i}}{E_{m}}\right)^{0.33} \sqrt[3]{\frac{1-v_{m}^{2}}{1-v_{i}^{2}}}
$$

where $n=0.90, v_{i}$, and $v_{m}$ are the Poisson's ratios of the top layer and half-space, respectively, $h_{i}$ is the thickness of the top layer, and $E_{i}$ and $E_{m}$ are the vertical elastic moduli of the top layer and half-space, respectively. The applicability Equations (2), (4) and (6) were verified by comparing calculated stresses and strains at the top of the subgrade layer of a pavement system consisting of the paver, bedding sand, base course, and subgrade layers with a finite element method (FEM) simulation. The results of this 
comparison are shown in Figure 2. The strains calculated by the ETM were slightly higher than those computed using the FEM, which gives a slightly conservative pavement thickness via damage laws.

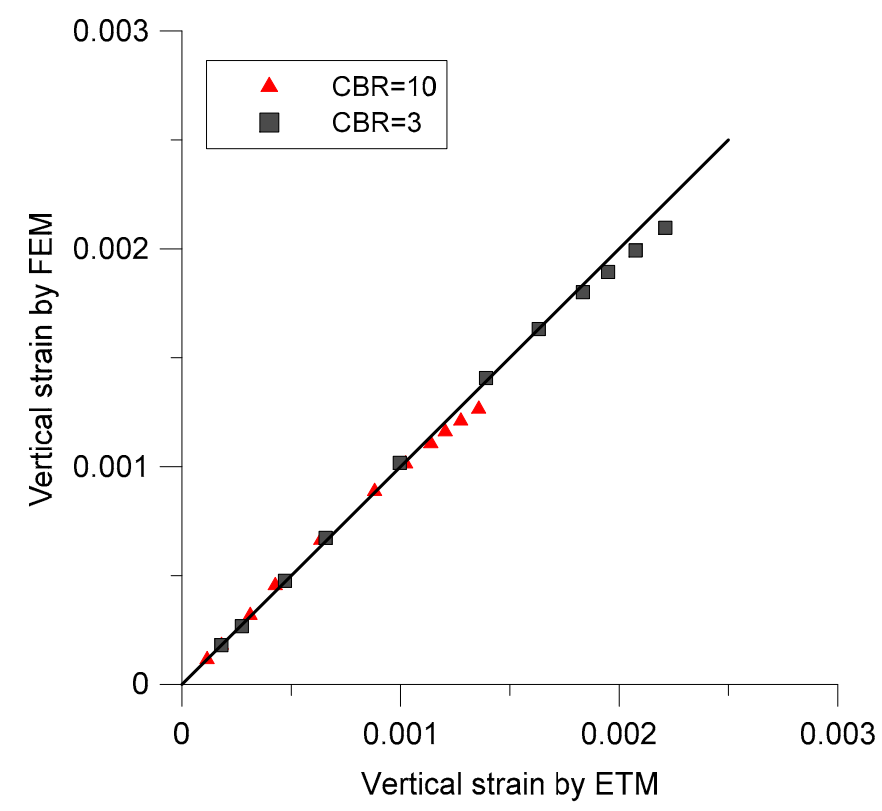

Figure 2. Comparison of vertical strains at the bottom of a $100 \mathrm{~mm}$ base course layer for two California Bearing Ratio (CBR) values. FEM: Finite Element Method; ETM: Equivalent Thickness Method.

\subsubsection{Damage Laws to Estimate the Life of the Pavement}

The unbound granular materials present in the pavement structure are assumed to fail due to the gradual accumulation of permanent rutting deformation in the subgrade layer. The fatigue life of bound layers is correlated with the maximum horizontal tensile strain at the bottom of the layer, and the permanent deformation fatigue life of the subgrade is correlated with the maximum vertical compressive strain at the top of the subgrade layer. Various methods can be used to relate the magnitude of these strains to the number of strain repetitions that a pavement can carry before failing [24]. The following equation, recommended by Edwards and Valkering (1974), was used to relate pavement permanent deformation with calculated strain [25]:

$$
\varepsilon=2.8 \times 10^{-2} \times N^{-0.25}
$$

where, $\varepsilon$ is the permissible subgrade compressive strain and $N$ is the number of strain repetitions.

For bound materials, the following fatigue criterion was adopted from Austroads [20].

$$
N=R F\left[\frac{\left(113000 / E^{0.804}+191\right)}{\mu \varepsilon}\right]^{12}
$$

where $N$ is the allowable number of load repetitions, $E$ is the vertical elastic modulus of the cemented material in $\mathrm{MPa}, \mu \varepsilon$ is the load-induced tensile strain (microstrain) at the base of the cemented material, and $R F$ is the reliability for cemented material fatigue. These fatigue criteria are valid for cemented materials with vertical elastic moduli varying from 2000 to 10,000 MPa.

For ESA-based designs, strains are calculated under a standard axle (a single axle dual tire configuration carrying $80 \mathrm{kN}$ load). Calculated maximum strains from relevant layers are then used with the fatigue laws, and the actual life of the pavement is calculated in terms of ESA. This calculated life (in terms of ESA) is then compared with the design life. If the actual life is lower than the design 
life, the process is repeated with a higher thickness of the target layer. The thickness is incremented until a satisfactory design is achieved.

\subsection{Pavement Layer System and Material Properties}

\subsubsection{Pavement Layer System}

A pavement layer system, as presented in Table 1, was used for calculating the design thickness of the base course and sub-base layers. A specific traffic load $\left(E S A=10^{6}\right)$ on the pavement along with specific subgrade CBR (either $2 \%$ or $4 \%$ ) was considered for the analysis, while base course/sub-base materials were varied and thus the elastic modulus of the base course/sub-base layers was varied accordingly. An illustration of the layer system is presented in Figure 3.

Table 1. Properties of different layers in the pavement structure containing base course and base course with sub-base.

\begin{tabular}{cccc}
\hline Layers & Typical Thickness $(\mathbf{m m})$ & Elastic Modulus (MPa) & Poison's Ratio \\
\hline Paver & 80 (for vehicle loading) & 3200 & 0.3 \\
\hline Bedding sand & 20 & 200 & 0.35 \\
\hline Base course & To be calculated $* / 100$ & Varying/350 & 0.35 \\
\hline Sub-base & To be calculated ${ }^{* *}$ & Varying & 0.35 \\
\hline Subgrade & Semi infinite & 40 & 0.40 \\
\hline
\end{tabular}

* When calculating base course thickness for the pavement with a granular layer; ${ }^{* *} 100 \mathrm{~mm}$ base course thickness with a vertical elastic modulus of $350 \mathrm{MPa}$ was used with a sub-base.

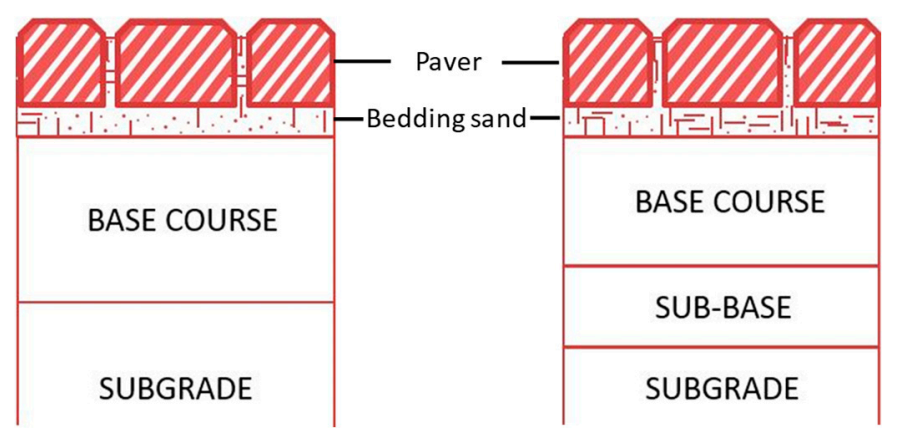

Figure 3. System layers considered for estimating design thickness: granular base course and granular base course with sub-base.

\subsubsection{Properties of Recycled Aggregates}

This study was focused on assessing the sustainability of concrete block pavements by comparing the use of two recycled aggregates (RA). These aggregates were denoted according to their source, namely Adelaide Resource Recovery (ARR), ResourceCo (RCO), and one virgin aggregate (VA) (20 mm crushed rock with fines sourced from a commercial quarry in Adelaide). These materials were characterized in detail in the geotechnical laboratory at the University of South Australia [16,17].

The aggregates were class 1 (nominal size $20 \mathrm{~mm}$ ) materials, which is suitable for pavements that can bear heavy traffic loads ( $\geq 5 \times 10^{6}$ ESA) [20]. All the materials were well-graded gravel with sand to silty gravel (GW-GM) according to the Unified Soil Classification System (USCS). Each material was passed through a $20 \mathrm{~mm}$ splitter to provide a consistent sample and the samples were prepared in accordance with Australian Standards. As per the particle size distributions (PSDs) shown in Figure 4, the VA had slightly more fines (11\%) than the recycled aggregates $(5 \%$ and $7 \%$ for ARR and RCO materials, respectively). All the tested aggregates satisfied the recommended PSDs proposed by the South Australian Department of Planning, Transport and Infrastructure (DPTI) [26]. 


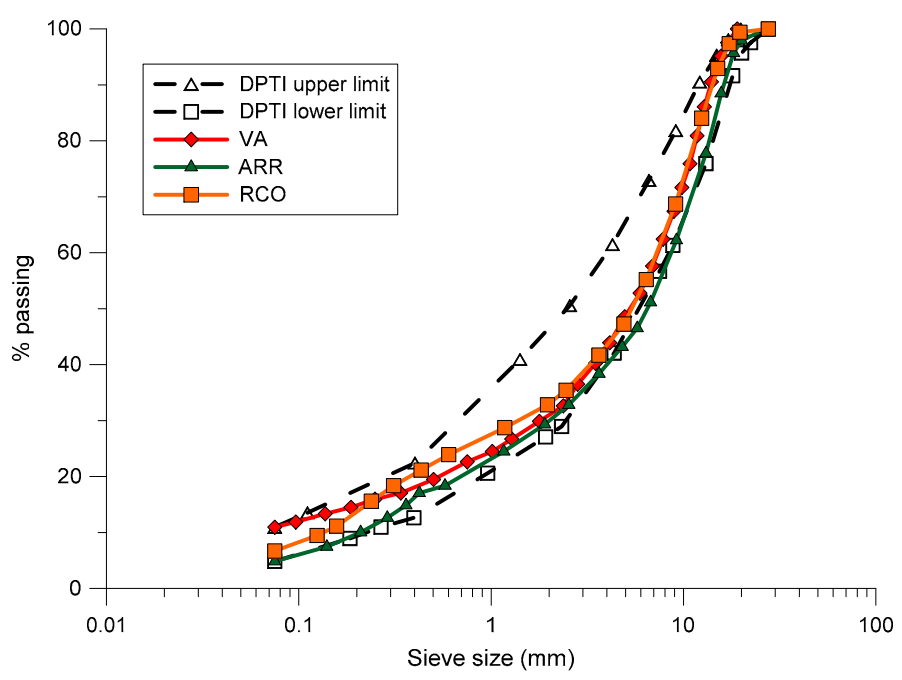

Figure 4. Particle size distribution of the tested aggregates compared with the Department of Planning, Transport and Infrastructure (DPTI) limits (source: data adopted from Gabr [27]). VA: Virgin Aggregate; ARR: Adelaide Resource Recovery; RCO: ResourceCo.

DPTI Part R15 [28] recommended undrained triaxial testing for appraisal of recycled products for pavements. Therefore, undrained monotonic triaxial tests on specimens of $100 \mathrm{~mm}$ in diameter and $200 \mathrm{~mm}$ high were conducted following the methods stated in AS 1289.6.2.2 [29]. The specimens were prepared at $90 \%$ and $60 \%$ optimum moisture contents (OMCs) and tested under three confining stresses, namely $\sigma_{\mathrm{r}}$ of $25 \mathrm{kPa}, 50 \mathrm{kPa}$, and $75 \mathrm{kPa}$ to determine their total shear strength properties (apparent cohesion, $\mathrm{c}$, and angle of friction, $\phi$ ) and elastic modulus. The tangential elastic moduli, $E$, of these aggregates were determined at $50 \%$ of the peak deviator stress. The $E$ value was increased with increasing $\sigma_{\mathrm{r}}$, as shown in Figure 5 . The $E$ values for recycled aggregates were consistently higher than for virgin aggregates. Although it is not a common scenario to have recycled aggregates with higher elastic modulus, the elastic modulus of aggregates might differ depending on its characteristics. Irrespective of comparing the moduli between virgin and recycled aggregates, the result here provided a range of elastic modulus for recycled aggregates, which was used for further parametric study analysis. It is noteworthy to report that a series of triaxial tests, including repeat load triaxial tests (RLTTs), was done by Gabr [27] and published elsewhere [30-32]. The reader should also be aware that there are advanced models for modulus that depend on material density, confining stress, octahedral stress, matrix suction, etc. [33,34]. However, Figure 5 represents a simple approach [28] to estimate the range of possible moduli.
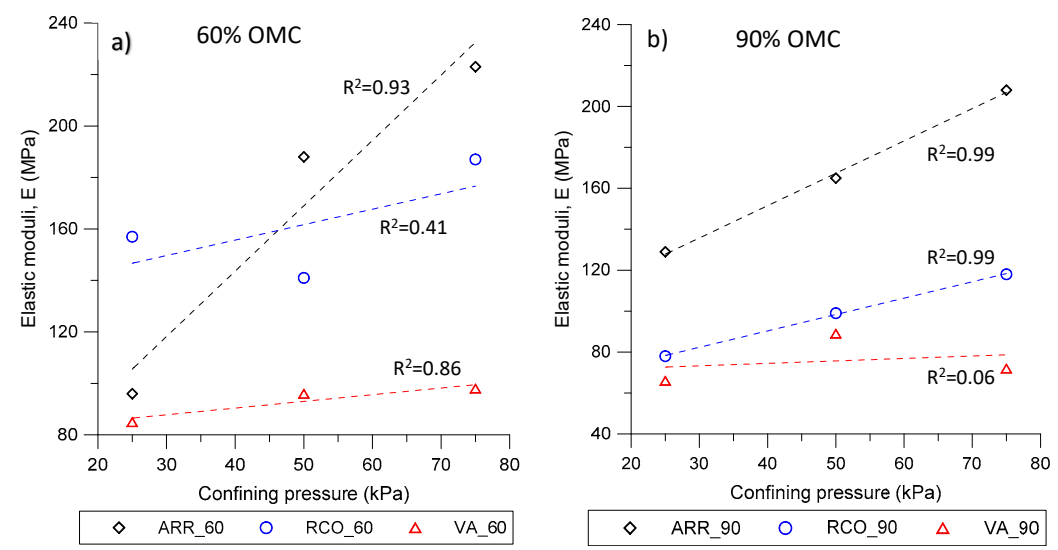

Figure 5. Measured elastic moduli of different base course aggregates in relation to confining pressure (a) for $60 \%$ optimum moisture contents (OMCs) and (b) for 90\% OMC (source: Gabr [27]). 


\subsection{Sustainability Analysis of Pavement Design}

\subsubsection{Sustainability Analysis}

To analyze the benefit-cost ratio (BCR) of using recycled aggregates in place of virgin aggregates, the life cycles of aggregates from their production to installation in the pavement base course/sub-base were assessed by adopting a "cradle-to-grave" approach. The life cycles of virgin and recycled aggregates are shown in Figure 6 depicting the energy consumption, $\mathrm{CO}_{2}$ emissions, and costs associated with each stage of the process. Natural aggregates, once extracted from the quarry and processed, are ready to use in the road base/sub-base. Recycled aggregates are sourced from construction and demolition waste. The construction waste material is processed in a recycling plant before it is ready to be used as road base/sub-base aggregate. Approximately $20 \%$ of the construction waste is non-recyclable and is deposited in a landfill. If the construction and demolition wastes are not recycled, then all the material has to go to the landfill, which is subject to a high government levy as well as processing costs.

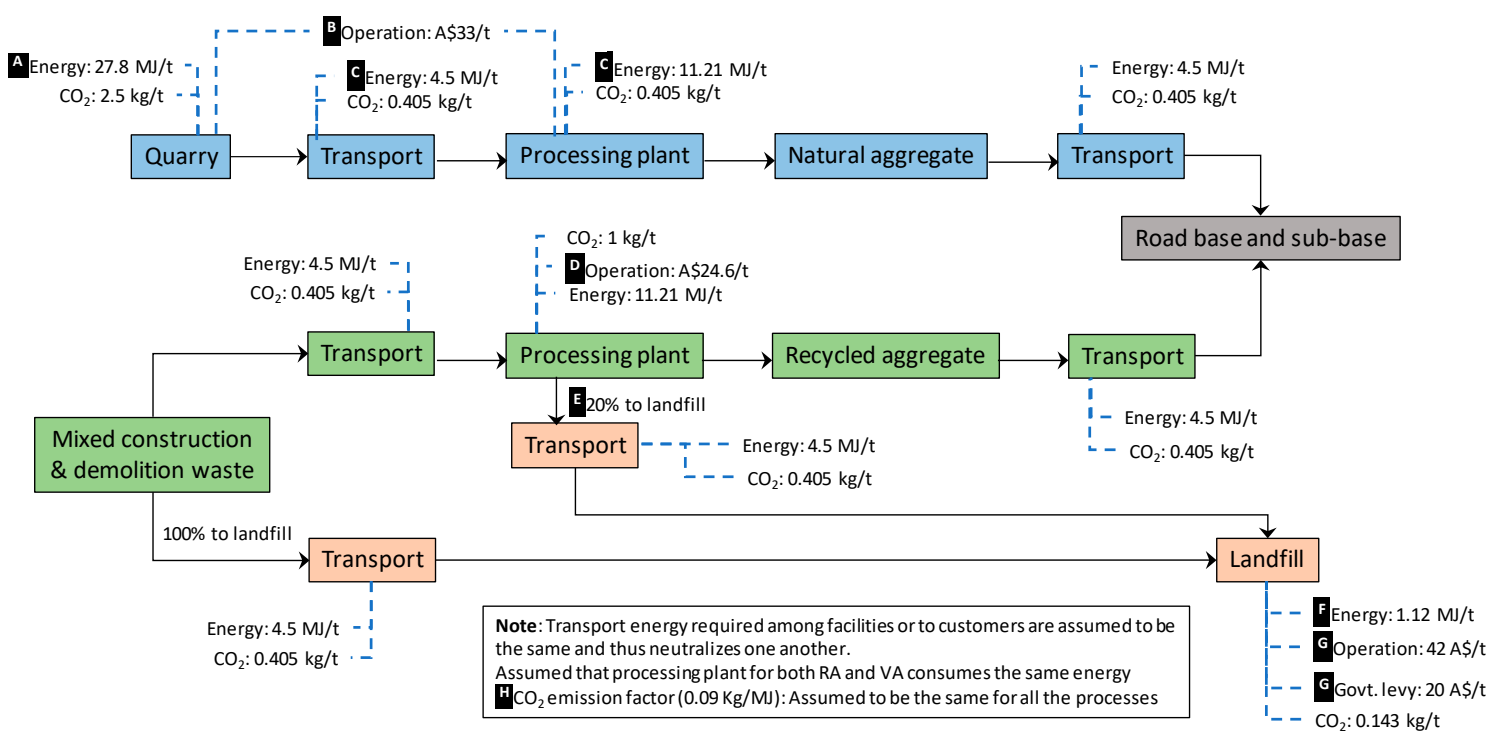

Figure 6. Life cycles of virgin and recycled aggregates and the associated costs in different phases. (Note: ${ }^{\mathrm{A}}$ [35]; ${ }^{\mathrm{B}}$ [36]; ${ }^{\mathrm{C}}$ [37]; ${ }^{\mathrm{D}}$ [38], [39]; ${ }^{\mathrm{E}}$ [40]; ${ }^{\mathrm{F}}$ calculated based on a processing plant [37], assuming the energy requirement by the machinery in a landfill site; ${ }^{\mathrm{G}}[39]$; ${ }^{\mathrm{H}}$ [41].)

The assumptions in this life cycle analysis (LCA) include the non-allowance for the variability of the energy required for transporting materials from a source location to the destination. Even though the cost of transporting materials might vary depending on the conditions, estimating the accurate transport cost is difficult. Therefore, a constant cost for transporting materials from one place to another was assumed in this research. Another assumption was that the same energy was required for both virgin and recycled materials at processing facilities/stations. Although this is a very gross assumption as the energy consumptions in the processing plants are highly variable, depending on the type of machinery used, it was compromised here in the life cycle assessment due to the lack of available data. In addition, the data were collected from a limited number of quarry and recycling facilities around the world. However, despite these assumptions, this LCA is able to demonstrate the differences in resource consumption, and it can be used to assess the potential economic and environmental benefits of using recycled aggregates in pavements.

Based on the conducted LCA, both the use value and option value of resources were considered for calculating the benefit-cost ratio (BCR) of using recycled aggregates in the pavement. The use value indicates the value derived from the physical use of a good [42], while the option value reflects the 
potential source of benefit in the future, as opposed to the actual present use value [43]. The BCR is a representation of the net benefits compared to the costs associated with any process [44]:

$$
B C R=\frac{\text { Value of net benefit }}{\text { Value of net cost }}
$$

where, in this research, the net benefit accounts for the direct and indirect economic benefits of using recycled aggregates, considering the use and option values of resources, respectively. The environmental benefit in the form of a potential reduction of $\mathrm{CO}_{2}$ emissions was also included in the net benefits. The net cost accounts for the expenditure associated with the process.

The use value considers the cost of the base course/sub-base aggregates and is the difference between the cost of using virgin and recycled aggregates. The option value represents the potential benefits that could be achieved in the form of the saved mining operation and land cost for not using virgin aggregates, and from the saved landfill cost of the recycled construction materials. The difference in emissions generated from the quarry and landfill site and that from the recycling site accounts for the net $\mathrm{CO}_{2}$ reduction (environmental benefit) for using recycled aggregates. A schematic diagram of how the use value, option value, and environmental benefits were calculated to estimate the BCR is shown in Figure 7.

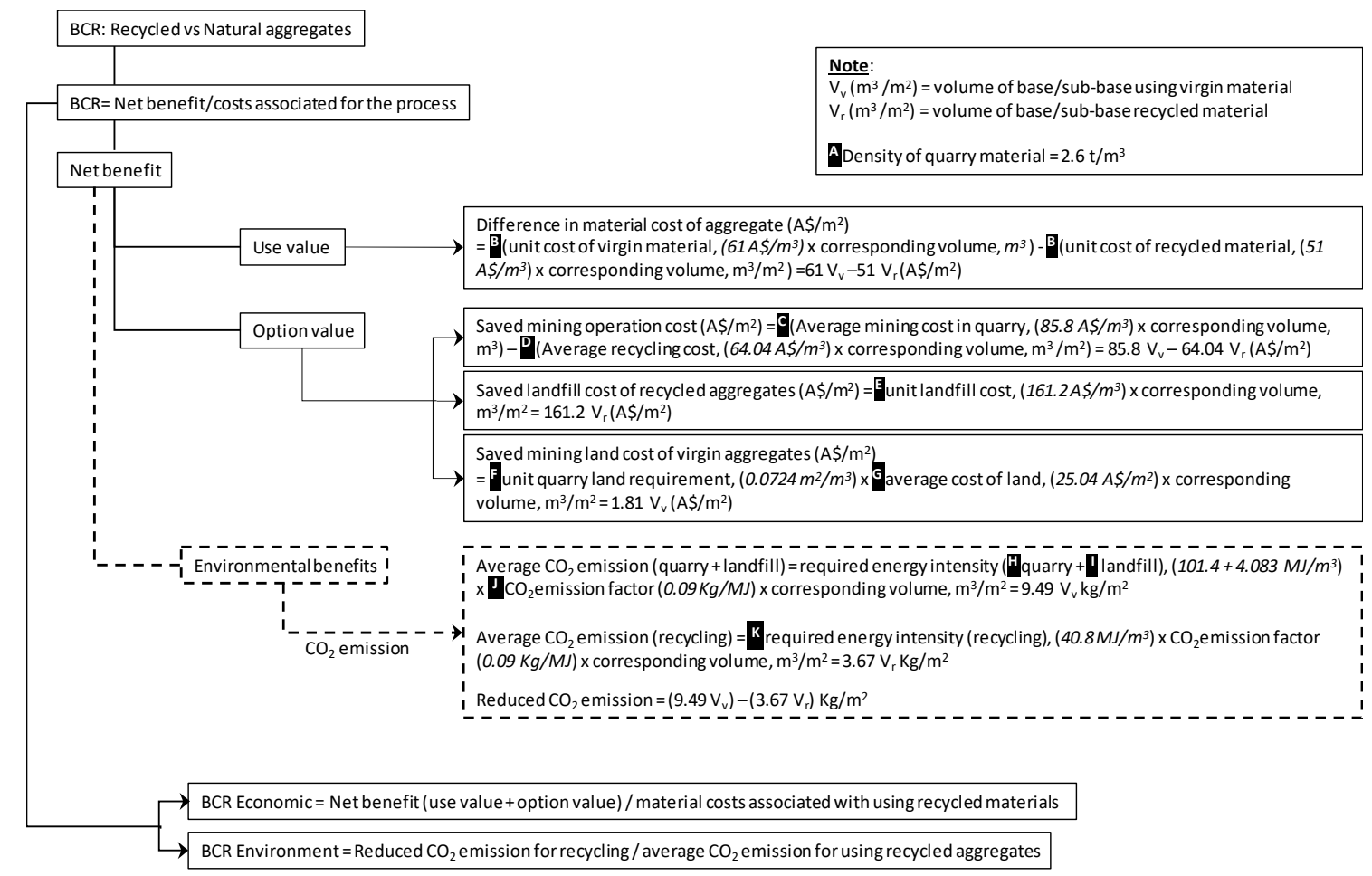

Figure 7. Schematic diagram of the method of calculating the benefit-cost ratio (BCR) considering the use value and the option value of resources. (Note: ${ }^{A}$ typical quarry material density obtained from Austroads [45]; ${ }^{B}$ market price of aggregates [46]; C, D, E, H, I, J, K calculated based on the values provided in Figure 6 (reference: ${ }^{\text {B }, ~ D, ~ G, ~ A ~ \& ~ C, ~ F, ~ H, ~ D ~}$ of Figure 6, respectively); ${ }^{\text {F }}$ based on a Gold Coast quarry, Australia [47]; $\mathrm{G}$ average of land prices, considering different percentage land uses [48].)

\subsubsection{Analyzing a Case Study}

A $7000 \mathrm{~m}^{2}$ CBP was constructed at the Leppington Bus Depot in NSW, Australia, in 2016, by InfraTech Geo Solutions [49], where the DesignPave software was used to estimate the sub-base course thickness, by keeping a specific base course depth of $300 \mathrm{~mm}$. An overview of the CBP design properties is provided in Figure 8. The CBP was visually inspected over four years and no noticeable 
damage/deterioration was observed. Four years is only a fraction of design life, however, the case study supports the applicability of this new mechanistic-empirical design method for Australian construction.

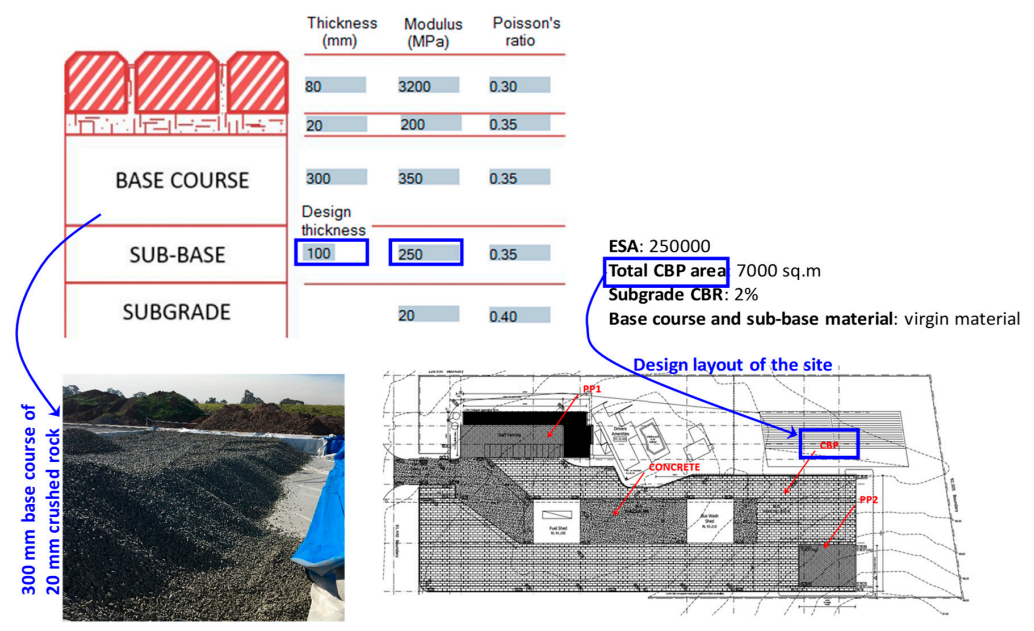

Figure 8. CBP design of the Leppington Bus Depot case study, used for analyzing the sustainability of an alternative design approach.

The alternative design approach of using recycled aggregates in the sub-base course considered the same pavement design properties and estimated the potential benefit that could be achieved in such a case for the whole $\left(7000 \mathrm{~m}^{2}\right)$ construction site (by adopting the methodology outlined in Figure 7).

\subsubsection{Analysis Scenarios}

The elastic modulus of aggregates varies with their material properties. Therefore, scenarios were generated in this research for a range of elastic moduli for virgin and recycled aggregates (Table 2). For each scenario, the base course/sub-base course depth was calculated, and this was used to estimate the volume $/ \mathrm{m}^{2}$ of pavement area. For the scenario analysis, the elastic modulus of virgin aggregate was varied from 100 to $250 \mathrm{MPa}$, while that for the recycled aggregates was varied from 100 to $350 \mathrm{MPa}$.

Table 2. Analyzed scenarios of aggregates for calculating the required volume of base course/sub-base.

\begin{tabular}{|c|c|c|c|c|c|}
\hline \multirow{2}{*}{\multicolumn{2}{|c|}{ Elastic Modulus (MPa) }} & \multicolumn{4}{|c|}{ Virgin Aggregates } \\
\hline & & 100 & 150 & 200 & 250 \\
\hline \multirow{6}{*}{ Recycled aggregates } & 100 & \multirow{6}{*}{\multicolumn{4}{|c|}{$\begin{array}{c}\text { Estimated volume of base course/sub-base for } \\
\text { each elastic modulus for: Virgin aggregates }\left(V_{\mathrm{V}}\right) \\
\text { Recycled aggregates }\left(\mathrm{V}_{\mathrm{r}}\right)\end{array}$}} \\
\hline & 150 & & & & \\
\hline & 200 & & & & \\
\hline & 250 & & & & \\
\hline & 300 & & & & \\
\hline & 350 & & & & \\
\hline
\end{tabular}

\subsection{Sustainability Analysis of Pavement Design}

The sustainability of a system is influenced by three components, namely economic efficiency, environmental benefits, and social acceptability. For a pavement system, social acceptability is not a significant influence compared to other structural designs for the same purpose. The design depth of the pavement was calculated considering the stability of the pavement. 


\subsection{Influence of Aggregate Properties: Pavement with Granular Layers}

A series of analyses was conducted to understand the effect of aggregate elastic modulus on the base and sub-base thickness. The paver and bedding sand properties were kept constant based on different reported laboratory tests [12], while the design thicknesses was plotted against design ESA in Figure 9a,b for different elastic moduli for the base course and sub-base aggregates, respectively. In general, for a given elastic modulus value, a minimum base course/sub-base thickness is required for lower ESA, then the thickness increases with increasing ESA. The minimum thickness of the base course/sub-base can be sufficient for higher ESA when the elastic modulus is higher. Increasing the base course/sub-base elastic modulus decreases the respective thickness required, and the effect is more pronounced at larger ESA values. It can be seen that the sensitivity of the elastic modulus on the base course/sub-base thickness is higher when considering low elastic moduli aggregates than for high elastic moduli aggregates.
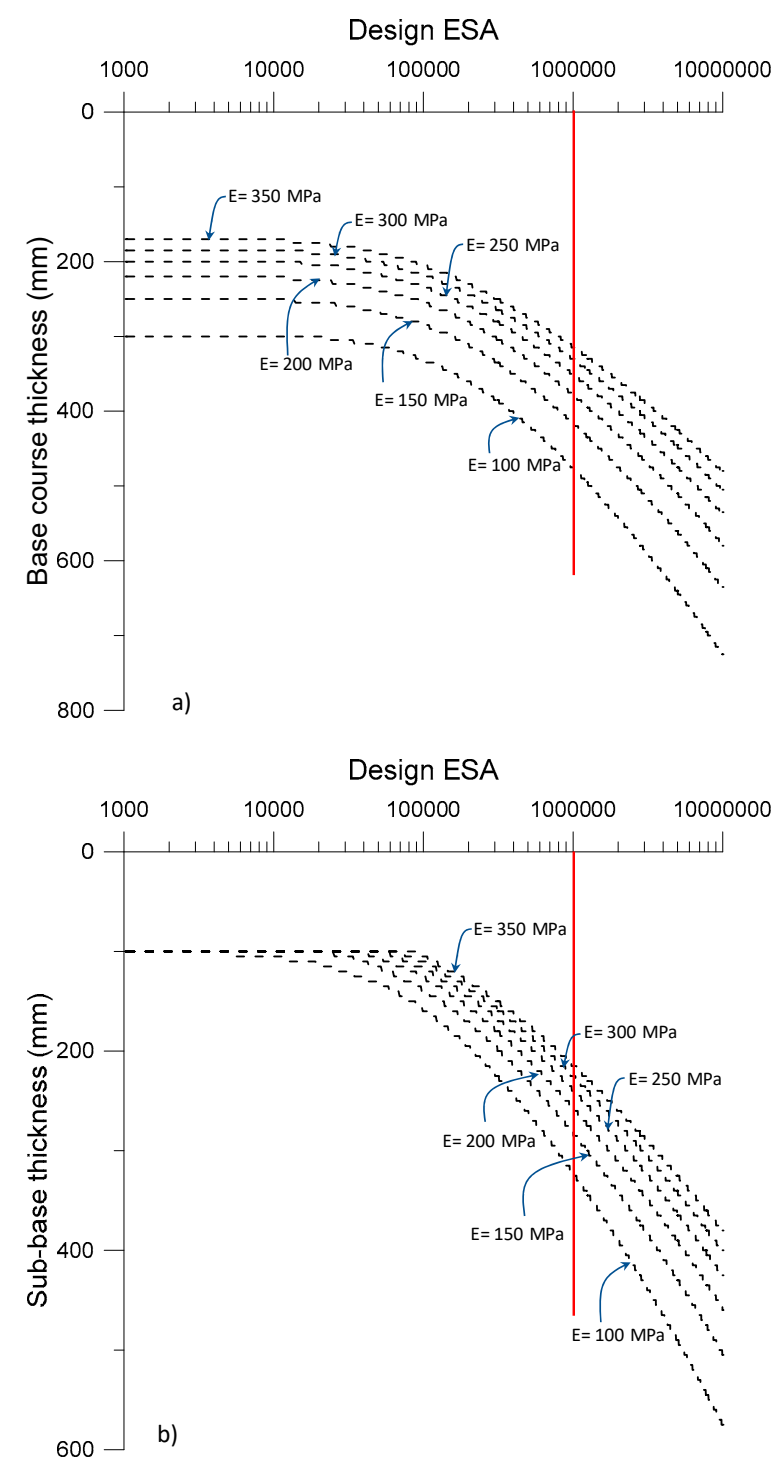

Figure 9. Influence of aggregate elastic modulus on the CBP design curve for paver thickness $=80 \mathrm{~mm}$, bedding sand thickness $=20 \mathrm{~mm}$, and subgrade CBR $=4 \%$ (a) base course thickness variations, (b) sub-base thickness variations.

As an example, for a pavement lying over a subgrade with $\mathrm{CBR}=4 \%$ and ESA $=1 \times 10^{6}$, the base course thickness is reduced by approximately $15 \mathrm{~mm}$ (from $330 \mathrm{~mm}$ to $315 \mathrm{~mm}$ ) for a base elastic 
modulus increase of $300 \mathrm{MPa}$ to $350 \mathrm{MPa}$, while the base course thickness reduction is approximately $60 \mathrm{~mm}$ (from $475 \mathrm{~mm}$ to $415 \mathrm{~mm}$ ) for the same $50 \mathrm{MPa}$ increase in elastic modulus from $100 \mathrm{MPa}$ to $150 \mathrm{MPa}$, as shown in Figure 9a. A similar trend is observed for sub-base thickness (Figure 9b). This emphasizes the importance of quality control of the base course/sub-base material in order to ensure the pavement design life.

\subsection{Case Study Analysis: Leppington Bus Depot}

The $7000 \mathrm{~m}^{2}$ of CBP that was constructed at the Leppinton Bus Depot was considered for assessing the economic and environmental benefits of using recycled aggregates in the pavement, and these benefits are shown in Table 3. The results illustrate the net benefits for a range of materials with different elastic moduli that might be produced from recycled construction materials. For example, a $7000 \mathrm{~m}^{2} \mathrm{CBP}$ can potentially reduce greenhouse gas emissions by $97,000 \mathrm{~kg}$ of $\mathrm{CO}_{2}$ in its lifetime by using recycled aggregates in the pavement.

Table 3. Accounted benefits for using recycled aggregates in the pavement system compared to using virgin aggregates $(\mathrm{E}=250 \mathrm{MPa})$.

\begin{tabular}{|c|c|c|c|c|c|c|c|}
\hline & \multicolumn{7}{|c|}{ Aggregate Elastic Modulus (MPa) } \\
\hline & 250 & 350 & 300 & 250 & 200 & 150 & 100 \\
\hline $\begin{array}{l}\text { Cost of using virgin base } \\
\text { course material }(\times 1000 \mathrm{~A} \$)\end{array}$ & 1345.05 & - & - & - & - & - & - \\
\hline \multicolumn{8}{|c|}{ Accounted net benefits of using recycled materials for a $7000 \mathrm{~m}^{2}$ pavement } \\
\hline $\begin{array}{c}\text { Visible costs/use value } \\
(\times 1000 \mathrm{~A} \$)\end{array}$ & & 345.45 & 291.90 & 220.50 & 149.10 & 24.15 & -172.20 \\
\hline $\begin{array}{l}\text { Hidden costs/option value } \\
\qquad(\times 1000 \mathrm{~A} \$)\end{array}$ & & 3204.27 & 3272.44 & 3363.32 & 3454.21 & 3613.26 & 3863.20 \\
\hline $\begin{array}{l}\text { Environmental benefits } \\
\text { (reduced } \mathrm{CO}_{2} \text { emissions) } \\
\qquad(\times 1000 \mathrm{~kg})\end{array}$ & & 135.03 & 131.18 & 126.04 & 120.89 & 111.90 & 97.76 \\
\hline
\end{tabular}

When comparing to the direct cost of materials, the lower market price of recycled aggregates provides benefits in most cases, except when there is a very low elastic modulus for the recycled materials. As the market price of materials regulates this benefit, there might be variations or even no benefits if the cost of recycled aggregates increases. However, the hidden cost or option value is an important factor here, which is not realized generally but incurs an overall cost to society. The hidden benefits accounted for in this research were much higher and thus controlled the overall benefit of the scenario. The results demonstrate that the hidden benefit increases even when the elastic modulus decreases. This is due to the increased benefit of not landfilling the recycled construction wastes.

The benefit-cost ratio (BCR) for any pavement system can be estimated by comparing the accounted net benefits of using recycled materials against the cost of using that aggregate. The following parametric study adopts the same pavement system as the case study site, and thus the case study site would show similar BCR scenarios (Figures 10 and 11a). 


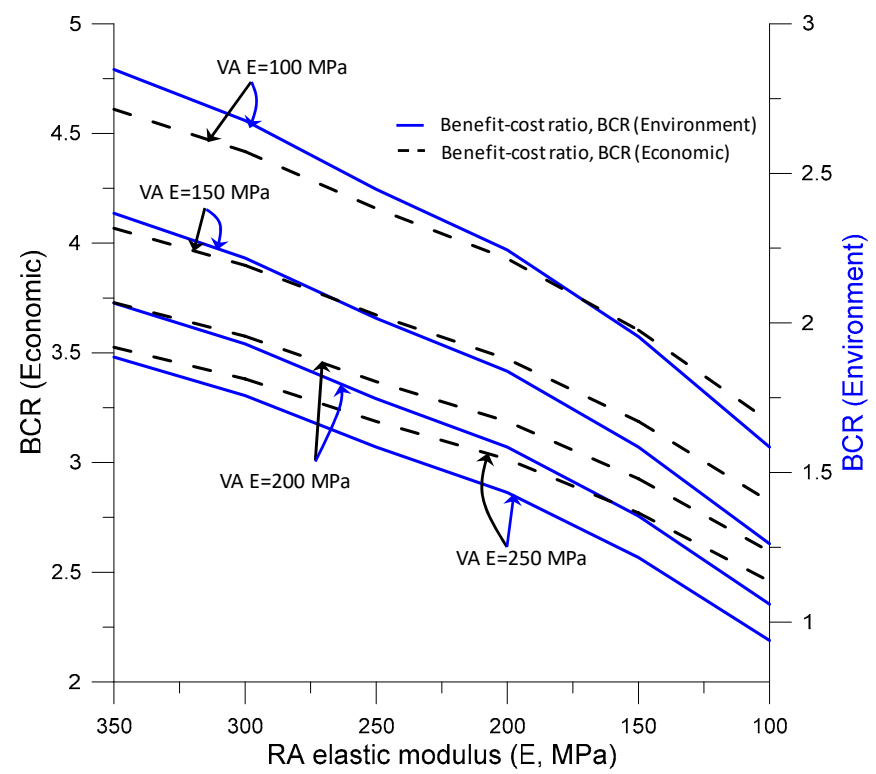

Figure 10. Economic and environmental BCRs when using recycled aggregates of different elastic moduli compared to a range of natural (virgin) aggregates in the sub-base (Note: RA = recycled aggregates; $\mathrm{VA}=$ virgin aggregates; $\mathrm{E}=$ elastic modulus, $\mathrm{MPa}$ ).

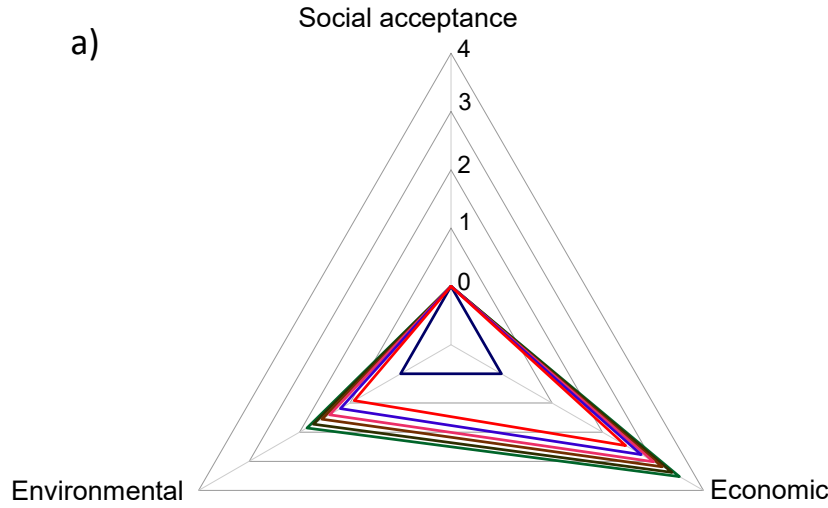

- VA E=250 MPa - RA E=250 MPa - RS E=150 MPa
- RA E=350 MPa - RS E=200 MPa - RA E=100 MPa
RA E=300 MPa

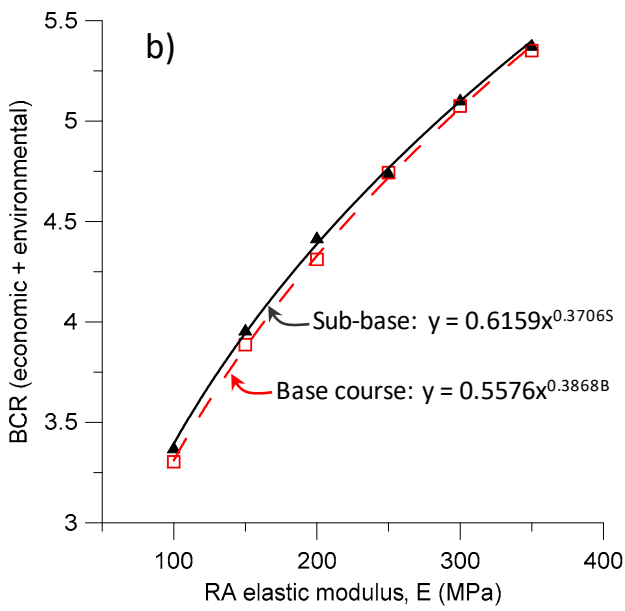

Figure 11. (a) BCR scenarios when using RA of varying elastic modulus in the sub-base, and (b) rate of change in BCR when using RA in the base course and sub-base, compared to a static VA E = $250 \mathrm{MPa}$.

(Note: $\mathrm{RA}=$ recycled aggregates; $\mathrm{VA}=$ virgin aggregates; $\mathrm{E}=$ elastic modulus, $\mathrm{MPa}$.)

\subsection{Parametric Study}

The parametric study in this research was conducted considering a pavement configuration that contains sub-base material along with a granular base course material lying below the concrete pavers and the bedding sand. A pavement system with only a base course layer would demonstrate a similar relationship, however, the sub-base configuration was selected to be consistent with the case study.

Various pavement design options (scenarios) were assessed against their economic and environmental benefits, demonstrating the extent of eco-efficiency achieved by different design options. Figure 10 shows the economic and environmental BCRs associated with using recycled aggregates of various elastic moduli (100 MPa to $350 \mathrm{MPa}$ ) when compared to using virgin aggregates of various elastic moduli (VA E $=100 \mathrm{MPa}, 150 \mathrm{MPa}, 200 \mathrm{MPa}$, and $250 \mathrm{MPa}$ ). The analysis indicates that both economic and environmental BCRs have a trend of reduction with a decrease in aggregate elastic modulus. However, the rate of change in environmental BCR is stiffer than the economic $\mathrm{BCR}$, signifying the importance of having a higher elastic modulus in recycled aggregates for gaining 
environmental benefits. A similar trend of BCR would be achieved in the case of recycled aggregates that are used in the base course, as shown in Figure 11b.

For a better understanding of the benefits of using recycled aggregates in a pavement sub-base, a comparison was performed against a specific virgin aggregate use (with elastic modulus $250 \mathrm{MPa}$, which is the most common value, Figure 11). Virgin aggregate is considered as the basis of comparison since it has no net benefits. In addition, social acceptance was considered to be consistent irrespective of the materials used in the pavement. The result shows that even recycled aggregates with a lower elastic modulus can offer higher environmental and economic efficiency than using virgin aggregates. The economic benefit is found to be much higher in all cases, and this is due to the landfill costs for construction wastes. Thus, when the wastes are recycled into aggregate material, the landfill cost reduces, and this results in higher economic benefits. As the material costs increase due to increased thickness requirements for base course and sub-base layers, this also reduces the benefit-cost ratio (Figure 11b). Materials with higher elastic modulus are associated with higher $\mathrm{CO}_{2}$ reductions, and thus this shows a higher BCR.

\section{Conclusions}

The algorithm for a newly developed software program that can be used for the design and analysis of concrete block pavements (CBPs), using a mechanistic-empirical approach, was discussed in this research. Parametric studies were conducted with the software to investigate the influence of aggregate elastic modulus on the design thicknesses of the base/sub-base layers. Thus, the sustainability concerning economic and environmental efficiency of using recycled aggregates, substituting the virgin aggregates, was analysed for a potential range of elastic modulus of recycled aggregates. The major findings of this study were:

- The new mechanistic-empirical design method via DesignPave was applied in many CBP designs in Australia. However, a $7000 \mathrm{~m}^{2}$ CBP at the Leppington Bus Depot in NSW, Australia, was constructed in 2016 and monitored for the last four years. No noticeable damage/deterioration at the case site supported the applicability of this new mechanistic-empirical design method for Australian construction.

- For the parametric analysis on the use of recycled aggregates, it was evident that the recycled aggregates were economically more efficient than the virgin aggregates when the total life cycle was considered.

- It was also evident from the research that recycled aggregates with higher elastic modulus would be influential in obtaining higher economic and environmental benefits.

Although the details of the use value and option value of resources (virgin and recycled aggregate) and how they incorporated in the sustainability analysis for different scenarios were presented. Some assumptions, as discussed earlier, have to be made for assessing the life cycle of aggregates. Therefore, these are the scopes for further research in assessing the life cycle of the materials and reducing the errors from assumptions.

Author Contributions: Conceptualization, M.M.R. and S.B.; formal analysis, M.M.R., A.T.Z.R. and A.I.; methodology, M.M.R. and A.I.; resources, S.B., M.M.R., M.R.K. and A.I.; validation, M.M.R., R.K., A.T.Z.R. and A.I.; writing—original draft, M.M.R. and A.I.; writing—review and editing, M.M.R., S.B., A.I., R.K. and A.T.Z.R. All authors have read and agreed to the published version of the manuscript.

Funding: Authors would like to acknowledge the financial to the development of the software, DesignPave V2.0, by the Concrete Masonry Association Australia (CMAA).

Acknowledgments: Authors would like to acknowledge Michael Koungras for providing the details of the case study. Authors also like to acknowledge proactive motivation and support on recycled aggregate from Peter Levett and the city of Salisbury.

Conflicts of Interest: The authors declare no conflict of interest. 


\section{References}

1. Shackel, B. Design and Construction of Interlocking Concrete Pavements; Elsevier Applied Science: New York, NY, USA, 1990.

2. Rollings, R.S. Concrete Block Pavement; Geotechnical Laboratory, U.S. Army Engineer Waterways Experiment Station: Washington, DC, USA, 1983.

3. Molenaar, A.A.A.; Moll, H.O.; Houben, L.J.M. Structural model for concrete block pavement. Transp. Res. Rec. 1984, 954, 16-27.

4. Shackel, B. The design of interlocking concrete block pavements for road traffic. In Proceedings of the 1st International Conference on CBP, Newcastle upon Tyne, UK, 1 December 1980; pp. 23-32.

5. Knapton, J. Concrete block pavement in the UK. In Proceedings of the 2nd International Conference on Concrete Block Pavement, Delft, The Netherlands, 10-12 April 1984; pp. 129-138.

6. CMAA. PA02: Concrete Segmental Pavement-Design Guide for Residential Accessways and Roads; Concrete Masonry Association of Australia: St Leonards, Australia, 2014; pp. 1-11.

7. DesignPave v2.0. A Mechanistic Design Software for Concrete Block Pavement; Rahman, M.M., Beecham, S., Eds.; Concrete Mawsonry Association Australia: Artarmon, NSW, Australia, 2018.

8. Kang, D.-H.; Gupta, S.C.; Ranaivoson, A.Z.; Siekmeier, J.; Roberson, R. Recycled Materials as Substitutes for Virgin Aggregates in Road Construction: I. Hydraulic and Mechanical Characteristics. Soil Sci. Soc. Am. J. 2011, 75, 1265-1275. [CrossRef]

9. CCAA. Use of Recycled Aggregates in Construction; Cement Concrete \& Aggregates Australia: St Leonards, NSW, Australia, 2008.

10. SV. Recycled Products in Pavement Construction: A Business Case for Councils to Use Local Recycled Products in Pavement Construction; Sustainability Victoria: Melbourne, Australia, 2015.

11. BORAL. Quarry Materials. 2020. Available online: https://www.boral.com.au/products/quarry-materials/allproducts? category=701 (accessed on 2 February 2020).

12. Shackel, B. The development and application of mechanistic design procedures for concrete block paving. Available online: http://www.sept.org/techpapers/1100.pdf (accessed on 24 May 2020).

13. Shackel, B. Computer methods for segmental concrete pavement design in Concrete segmental paving workshop. In Proceedings of the Australian Road Research Board Conference, Perth, Australia, 9-12 November 1992; pp. 28-46.

14. Shackel, B. Computer-aided design and analysis of concrete segmental pavements. In Proceedings of the International Workshop on Interlocking Concrete Pavements, Melbourne, Australia, 1-2 September 1986; pp. 57-76.

15. Shackel, B. Progress in the evaluation and design of interlocking concrete block pavements. In Proceedings of the Biennial Conference of the Concrete Masonry Association of Australia, Brisbane, Australia; 1980; pp. 1-8.

16. Shackel, B.; Arora, M.G. The evaluation of interlocking block pavements-An interim report. In Proceedings of the Conference of Concrete Masonry Association, Sydney, Australia, 20 March 1978.

17. Mahapatra, G.; Kalita, K. Effects of Interlocking and Supporting Conditions on Concrete Block Pavements. J. Inst. Eng. India 2018, 99, 29-36. [CrossRef]

18. Houben, L.J.M.; Molenaar, A.A.A.; Fuchs, G.H.A.M.; Moll, H.O. Analysis and design of concrete block pavements. In Proceedings of the 2nd International Conference on CBP, Delft, The Netherlands, 10-12 April 1984; pp. 86-99.

19. Shackel, B.; Lim, D.O.O. Mechanism of paver interlock. In Proceedings of the 7th International Conference on Concrete Block Paving (PAVE AFRICA 2003), Sun City, South Africa, 12-15 October 2003.

20. Austroads. Guide to Pavement Technology Part. 2: Pavement Structural Design; AGPT02-12; Austroads Ltd.: Sydney, Australia, 2012.

21. Rahman, M.M.; Beecham, S.; McIntyre, E.; Iqbal, A. Mechanistic design of concrete block pavements. In Geotechnics and Transport Infrastructure; Australian Geomechanics Society: Melbourne, Australia, 2018.

22. Boussinesq, J.V. Application des Potentiels à l'Étude de l'Équilibre et du Mouvement des Solides Élastiques; Gauthier-Villars: Paris, France, 1885.

23. Odemark, N. Investigations as to the Elastic Properties of Soils and Design of Pavements According to the Theory of Elasticity; Statens Vagins Institute: Stockholm, Sweden, 1949.

24. Azam, A.M.; Cameron, D.A.; Rahman, M.M. Permanent strain of unsaturated unbound granular materials from construction and demolition waste. J. Mater. Civ. Eng. 2015, 27. [CrossRef] 
25. Edwards, J.M.; Valkering, C.P. Structural design of asphalt pavements for road vehicles—The influence of high temperatures. Highw. Road Constr. 1974, 42, 1-9.

26. DPTI. Supplement to the Austroads Guide to Pavement Technology Part. 2: Pavement Structural Design; Department of Planning, Transport and Infrastructure: Adelaide, South Australia, 2018.

27. Gabr, A.R.G. Repeated Load Testing for Primary Evaluation of Recycled Concrete Aggregate in Pavements. Ph.D. Thesis, University of South Australia, Adelaide, Australia, October 2012.

28. DPTI Part R15. Supply of Pavement Materials; Department of Planning, Transport and Infrastructure: Adelaide, Australia, 2011; pp. 1-12.

29. AS 1289.6.2.2. Methods of Testing Soils for Engineering Purposes-Soil Strength and Consolidation Tests-Determination of Shear Strength of a Soil-Direct Shear Test Using a Shear Box; Australian Standard: Sydney, Australia, 1998.

30. Gabr, A.R.; Mills, K.G.; Cameron, D.A. Repeated Load Triaxial Testing of Recycled Concrete Aggregate for Pavement Base Construction. Geotech. Geol. Eng. 2013, 31, 119-132. [CrossRef]

31. Gabr, A.; Cameron, D. Properties of recycled concrete aggregate for unbound pavement construction. J. Mater. Civ. Eng. 2012, 24, 754-764. [CrossRef]

32. Gabr, A.; Cameron, D. Permanent strain modeling of recycled concrete aggregate for unbound pavement construction. J. Mater. Civ. Eng. 2013, 25, 1394-1402. [CrossRef]

33. Azam, A.M.; Cameron, D.A.; Rahman, M.M. Model. for prediction of resilient modulus incorporating matric suction for recycled unbound granular materials. Can. Geotech. J. 2013, 50, 1143-1158. [CrossRef]

34. Cameron, D.A.; Azam, A.H.; Rahman, M.M. Recycled Clay Masonry and Recycled Concrete Aggregate Blends for Pavements. In GeoCongress 2012 - State of the Art and Practice in Geotechnical Engineering, GSP-225; Hryciw, R.D., Athanasopoulos-Zekkos, A., Yesiller, N., Eds.; ASCE: Oakland, CA, USA, 2012; pp. 1532-1541.

35. Smith, L.; Losee, S. Greenhouse Gas Assessment for the Gold Coast. Quarry: Appendix HH; Katestone Environmental Pty Ltd: Milton, QLD, Australia, 2013.

36. AEPL. Economic Contribution of the Extractive Industries in Victoria; Access Economic Pty Limited: Kingston, VIC, Australia, 2006.

37. Coelho, A.; Brito, J.D. Environmental analysis of a construction and demolition waste recycling plant in Portugal-Part. I: Energy consumption and CO2 emissions. Waste Manag. 2013, 33, 1258-1267. [CrossRef] [PubMed]

38. DSEWPC. Construction and Demolition Waste Guide-Recycling and Re-Use Across the Supply Chain; Department of Sustainability, Environment, Water, Population and Communities, Commonwealth of Australia: Canberra, Australia, 2011; p. 57.

39. Tam, V.W.Y. Economic comparison of concrete recycling: A case study approach. Resour. Conserv. Recycl. 2008, 52, 821-828. [CrossRef]

40. Rosado, L.P.; Vitale, P.; Penteado, C.S.G.; Arena, U. Life cycle assessment of natural and mixed recycled aggregate production in Brazil. J. Clean. Prod. 2017, 151, 634-642. [CrossRef]

41. DEE. National Greenhouse Accounts Factors; Department of the Environment and Energy, Commonwealth of Australia: Canberra, Australia, 2019; p. 85.

42. Callan, S.J.; Thomas, J.M. Environmental Economics and Management-Theory, Policy and Applications; IRWIN: Burr Ridge, IL, USA, 1996; p. 725.

43. FAO. Forest Valuation for Decision Making_Lessons of Experience and Proposals for Improvement; Food and Agriculture Organization of the United Nations: Rome, Italy, 1997.

44. TMR. Cost Benefit Analysis Manual and CBA6. In Technical Guide; State of Queensland: Brisbane, Australia, 2011.

45. RMS. Roads and Maritime Supplement to Austroads Guide to Pavement Technology_Part 2: Pavement Structural Design; NSW Government: Sydney, Australia, 2018.

46. SoilWorx. Gravel \& Aggregates. 2020. Available online: https://www.soilworx.com.au/shop/bulk-andquarry-products/gravel-and-aggregates (accessed on 10 February 2020).

47. DSDMIP. Initial Advice Statement: Appendix C. In Gold Coast. Quarry; Queensland Government: Brisbane, Australia, 2009. 
48. EPA. Land. In State of the Environment Report; Environment Protection Authority, South Australia: Adelaide, Australia, 2008.

49. InfraTech. Leppington Bus Depot Preliminary Pavement Design Report; Infra Tech Geo Solutions: Perth, Australia, 2016.

(C) 2020 by the authors. Licensee MDPI, Basel, Switzerland. This article is an open access article distributed under the terms and conditions of the Creative Commons Attribution (CC BY) license (http://creativecommons.org/licenses/by/4.0/). 